\title{
A new measurement system to determine stiffness distribution in machine tool workspace
}

\author{
Piotr Pawełko ${ }^{1}$. Daniel Jastrzębski ${ }^{1} \cdot$ Arkadiusz Parus $^{2} \cdot$ Joanna Jastrzębska $^{3}(1)$
}

Received: 19 May 2020 / Revised: 3 February 2021 / Accepted: 27 February 2021 / Published online: 11 March 2021

(c) The Author(s) 2021

\begin{abstract}
This paper presents an innovative system determining machine tool quasi-static stiffness in machining space, so-called Stiffness Workspace System (SWS). The system allows for the assessment of the accuracy of a machine which has become a vital aspect over past years for machine tool manufacturers and users. Since machine tools static stiffness is one of the main criteria using to evaluate the machines' quality, it is crucial to highlight the relevance of experimental and analytical stiffness determination methods. Therefore, the proposed method is applied to estimate the spatial variation of static stiffness in the machine tool workspace. This paper describes the SWS system-its design, working principle, mounting conditions and signal processing. The major advantage of the system is the capability to apply forces of controlled magnitude and orientation as well as simultaneously measure the resulting displacements. The obtained results give possibility to estimate and evaluate static stiffness coefficients depending on the position and direction under loaded conditions. The results confirm the validity of the analyses of spatial stiffness distribution in the machine workspace.
\end{abstract}

Keywords Machine tool $\cdot$ Static stiffness $\cdot$ Measurement system $\cdot$ Signal processing $\cdot$ FEM

\section{Introduction}

Accuracy of machining process is significantly influenced by the actual state of the machine tool components and their cooperation. For the purpose of this paper, the system of machine tool elements is called MTHW system (machine tool-tool-holder-workpiece). Important roles in this system play: characteristics of individual system components, an assembling technology of the machine, physical phenomena taking place during machining process, changeable machining conditions or control systems [1]. All these aspects can impact on the interactions between the tool and

Joanna Jastrzębska

joanna.jastrzebska@zut.edu.pl

1 Department of Mechatronics, Faculty of Mechanical Engineering and Mechatronics, West Pomeranian University of Technology, Szczecin, Poland

2 Environmental Measurement Laboratory, Faculty of Mechanical Engineering and Mechatronics, West Pomeranian University of Technology, Szczecin, Poland

3 Department of Production Management, Faculty of Mechanical Engineering and Mechatronics, West Pomeranian University of Technology, Szczecin, Poland the workpiece. However, all these mentioned effects might be weakened or empowered depending on the stiffness of the MTHW system. This means that ensuring appropriate level of stiffness during cutting is one of the basic criteriaboth, of machine tool design and, then, while planning the cutting parameters. This creates the need for development the stiffness-measuring method as well as building a system that enable to determine the stiffness values in the specific position in the machine workspace. It is worth pointing out, that the stiffness level should be appropriate for parameters during finish machining as it is the most demanding stage in metal cutting.

Based on the analysis of the-state-of-the-art in the field of stiffness measuring systems, it can be claimed that there is no common standardized approach of machine tool stiffness studies. Methods and guidelines for tests for machining centres under finishing conditions are specified in the ISO 230 [2] series, as well as in ISO 10791-7 [3] which deals with the verification of kinematic accuracy of the machine. However, these standards concern testing conditions accounting only for geometric errors and deviations resulted from quasi-static load. As machine tool stiffness depends on various effects, e.g., the deflections of machine tool components and properties of connections between them, it is 
difficult to determine the stiffness of MTHW system under machining conditions. Thus, it seems reasoned to omit a difficult to monitor machining process while stiffness studies. Hence, the attempts of estimating stiffness coefficient by experiments can be based on loading simulations tests that substitute the real cutting force. In this approach, an adequate measurement of the displacements of the tool and the workpiece should be ensured.

Choosing the proper value of stiffness is an important requirement in the design process of machine tool. During the design stage, the machine's stiffness can be predicted using modelling techniques. Currently, the finite element method (FEM) is widely used for this purpose. Modelling of MTHW system is difficult due to the physical properties of the machine structural components and contact joints. The use of FEM most often results in multidimensional nonlinear models. Solving such models is not effective, especially while respecting calculations of stiffness in different positions of the workspace. Therefore, as might be expected, more effective modelling methods are being searched and developed.

David Te-Yen Huang et al. in work [4] presented a hybrid method of modelling for stiffness analyzing of machine tools. This method is based on combining different types of FEM elements in one model. Authors showed higher efficiency and accuracy of the proposed method in compare to the single module method (SMM), in which individual elements of machine tool structure are analyzing as separated modules. For both methods, investigations and calculations were carried out and the results showed the superiority of HMM over SMM. For example, using HMM to obtain the stiffness permits to avoid complicated and problematic transformations of external loads. Also, proposed HMM allows to avoid the local deformation effects that can be caused by non-uniform distribution of node forces. This may improve accuracy of calculations and should help to avoid overestimation of the stiffness of the module. Also, Jastrzębski [5, 6] described an application of the hybrid finite elements method for static calculations of load-carrying system of a milling machine. Presented results showed that there is a qualitative similarity of FEM method and hybrid method used to static stiffness analysis. Furthermore, a strong coupling between contact connections and deformations of machine tool elements was observed. Salgado et al. [7] analysed the change of machine tool stiffness model under cutting forces. In this work the stiffness of elements of the system (formed by machine-tool, shank, toolholder, collet and tool) modelled and simplified as cantilever beams were investigated. Moreover, the load and displacement measurements were conducted to estimate the stiffness and errors appear on the machined surfaces. Then, analytically obtained results of stiffness model were compared with the experimental results. Also, Dunaj et al. [8] presented a methodology to determine the stiffness of machine tool load-bearing system using substructuring method. They proposed a simplified model of stiffness of the linear guide with a preload (regardless of used types of carriages), moreover, they developed an equivalent contact model which allows to replace the ball with four rod elements of equivalent stiffness. The model and obtained results were compared with experimental results, which showed that the proposed method shortens the computation time and does not affect the accuracy of the results. Wu et al. [9] proposed to derive the stiffness matrixes for revolute pair elements and guideway-slider subsystem, of a 5-DOF hybrid machine tool with actuation redundancy. Some elements of the machine were determined as beam elements, for which stiffness matrixes were calculated, then validated by the finite element analysis model and experiments.

All kinds of analytical investigations and computer simulations need to be verified on real objects. The applied modelling method, the model structure and its parameters should be verified. Therefore, it is necessary to conduct experimental investigations that allow measuring loads and displacements at a certain position in the workspace. Albercht et al. [10] presented a method of measuring cutting force during machining. An indirect force measurement was proposed. The load was determined from measurements of displacements of rotating spindle shafts using capacitance displacement sensors. The advantage of this method is a noncontact measurement of static and dynamic changes of the gap between the sensor face and the spindle. Furthermore, various position configurations of sensors were analysed and the influence of several factors (like temperature or spindle rotation velocity) influencing the measurement results were considered. Also, Sarhan and Matsubara in [11] focused on cutting force monitoring in the context of machine tool spindle stiffness. They used various measurement instruments, such as: eddy-current displacement sensors or thermocouples to detect and investigate the radial motion of the rotating spindle and its stiffness. The authors showed, as a case study, that spindle stiffness changes due to the various temperature and speed of the spindle.

Because of the problems of controlling and measuring loading force during machining experiment, the methods of loading test are being developed. To substitute the machining experiment, Xiaopeng Wang et al. [12] presented a noncontact electromagnetic loading device. Their approach focuses how to solve the problems of inadequate loading and dynamic performance measurement of high-speed (HS) spindle. Electromagnetic loading excites the spindle at high speed rotating using sweep excitation. The proposed method allows determining the radial static and dynamic stiffness of the spindle. However, the drawback of the method is "that the relationship between the resonant frequency and rotating speeds cannot be identified" that influence the variation regularity of stiffness. Matsubara et al. [13] also studied 
dynamic stiffness of a rotating HS spindle using magnetic loading device. A magnetic loading device was used to simulate loading conditions and the spindle displacement was measured using eddy-current-type sensors. The analysis was concentrated mainly on dynamic aspects, such as natural frequency and temperature changes of the spindle. Also, the work [14] by Rantatalo et al. described a contactless testing method to analyse lateral vibrations of the rotating HS spindle which based on magnetic excitation. Electromagnets were used to excite the tool, while the spindle displacements were measured by inductive sensors. The measurement device was supported by FEM simulations. The analysis included the gyroscopic moment, bearing stiffness or different spindle speeds related to the stiffness.

Studies combining prediction of machine tool stiffness analytically and its experimental verification were described in [15] by Gao et al. The static stiffness field of the machining space was estimated. Furthermore, the effect of the six-directional static stiffness was analysed due to possibility of reducing of the machining errors. The results from modelling were proved with results obtaining by experiment based on load simulation device (hydraulically powered). The authors greatly confirmed the importance of stiffness analysis for "the machine tool design, processing design, and the structural design of machine tools based on the employed machining technology" [15]. Also, Archenti et al. [1, 16, 17] used the variation method for identifying parameters of individual joints of machine tool. Structural elements of machine tool linked to each other are represented by elastic links. The identification is based on the results of stiffness measurements using the loaded double ball bar [1, 17]. This approach requires a sequential position change of the measuring system to various points in the machining space.

Analysis of the state of the art brings to the fore the need to know the stiffness of machine tools in the field of their design process as well as utilization. The information about stiffness in specific direction of axis of machine tool for changeable loads' direction is crucial in finish machining. Hence, the stiffness studies should be conducted for finishing conditions (real load values) and the spatial stiffness caused by a variation of the position of the machine components in the machining space should be investigated.

This work presents the concept of novel device to investigate the stiffness of machine tools. The idea of the system is to implement the load with simultaneous multi-point measurements of displacements. The use of three-direction loading system simulates machining conditions (different components of a cutting force). The compact of the device provides the possibility of testing at many points in the machining space. Moreover, it allows determining the variability of stiffness coefficients resulting from changeable configurations of the machine tool. The remaining of the paper is organized as follows. First, the device's concept is described and a numerical analysis due to the device stiffness is presented. Second, verify tests for the device were carried out. Finally, the methodology of determining the quasi-static stiffness from obtained results (signals) is presented.

\section{System for determination of stiffness in machine tool workspace}

Providing adequate functionality of proposed SWS is necessary to determine the stiffness variations in the workspace of the machine. This means, that the system should allow gathering information about displacements of the functional point in different locations in the machine tool space. It was assumed that the testing device should meet the following requirements $[18,19]$ :

- the stiffness of the system should not influence the measurements of a machine tool (or if the system's stiffness impacts the measurements-its effect should be included),

- there should not be any limitation of the system positioning in the workspace,

- the system should be compact and portable (i.e., easy and fast rearranging in the workspace).

\subsection{The concept of the stiffness measurement system}

Considering that the concept of the system needs to meet the requirements, the idea of the system work is described. The realization of the idea is possible only if the concept suits the requirements fully. Designed system for quasi-static stiffness measurements provides simultaneous generation of three independent components of the load. It is worth pointing out that the three loads can be coincide with the machine tool $\mathrm{X}, \mathrm{Y}, \mathrm{Z}$-axes, but it is not obligatory. Furthermore, Fig. 1

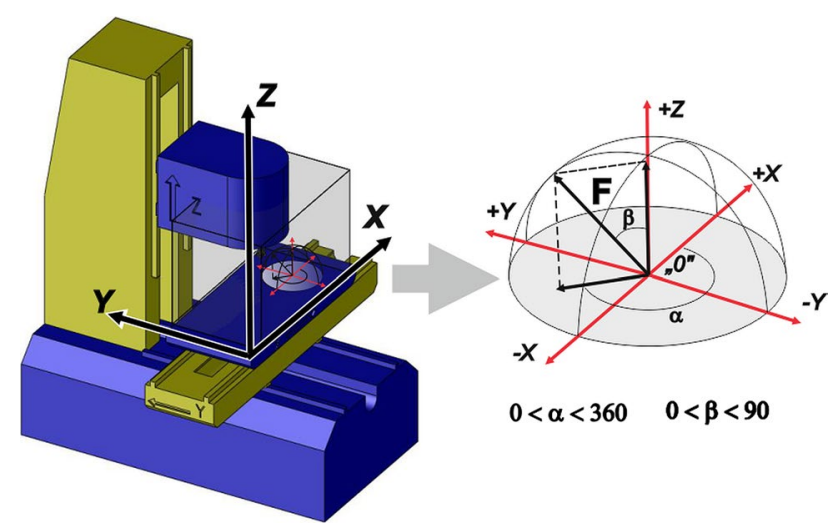

Fig. 1 Directions of loads generated by SWS 
shows that the load (marked as vector F) can be directed into any point in space.

The SWS consists of three main systems: the load generation system, the measurement system and the system of control and data registration.

The SWS contains of two basic mechanical parts-an active and a passive. The active part is the body of the loading device. It is fastened directly to the table of the machine tool. The load is generated by hydraulic actuators that are built in the device body. To power the hydraulic actuators the hydraulic power pack is used which also controls the values of loads' component. The passive part of the device is a solid arbour (representing a cutting tool) which is fastened into the spindle tool holder (like a typical milling tool). The summarized concept of the SWS can be seen in Fig. 2.

Due to generated forces the active and the passive parts of SWS system are subject to relative displacements. The displacements are measured using the system of 12 contactless inductive sensors that setup configuration is presented in Fig. 3. Displacement sensors are fastened to the body of the device and they are oriented in the same directions as actuators, respectively. Two pairs of displacement sensors respect to one pair of actuators in each direction, as it is shown

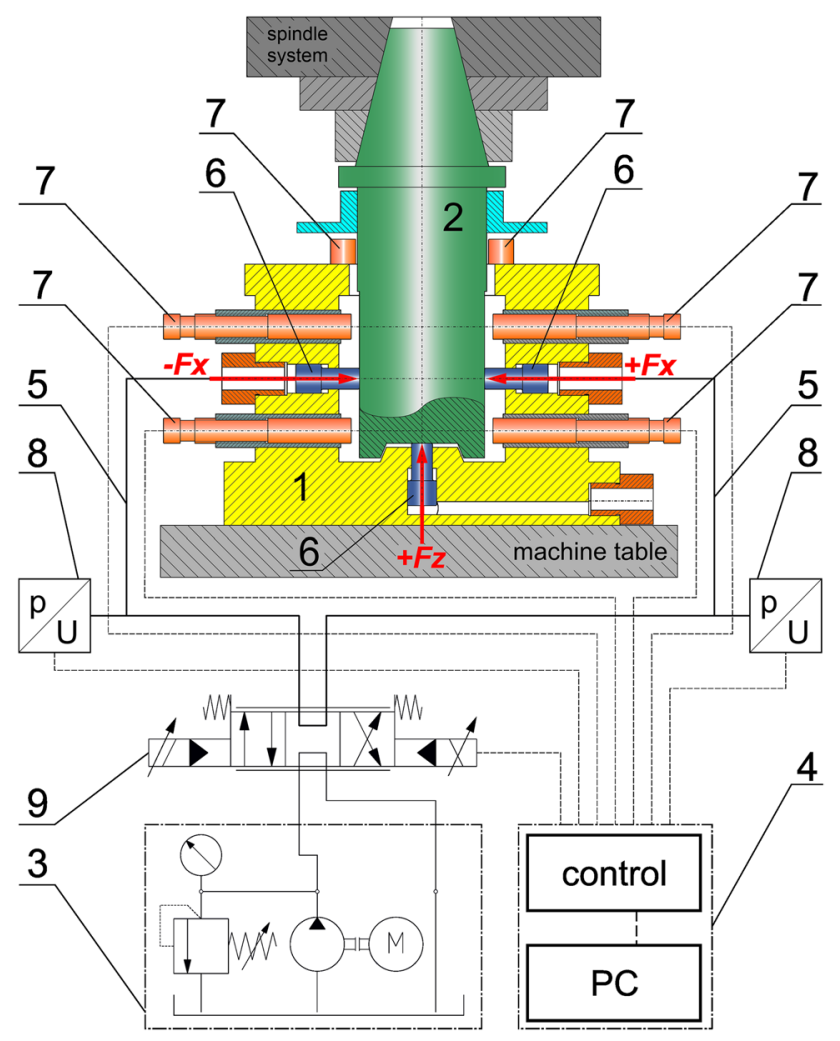

Fig. 2 Stiffness workspace system (SWS): 1-loader body, 2-solid arbour, 3-HPU, 4-control and measurement system, 5-hydraulic hoses, 6-hydraulic cylinders, 7-displacement sensors, 8-pressure transducer, 9-hydraulic pressure proportional valve

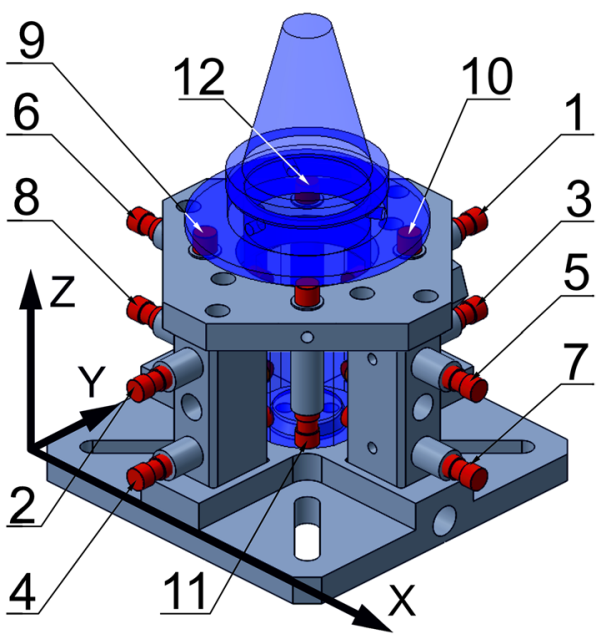

Fig. 3 Displacement sensors positions

in Fig. 4a. This arrangement allows determining rotational displacements. Moreover, the solution, that two displacement sensors are oppositely oriented in one direction, can minimize the measurements errors. However, along vertical axis of a machine tool this idea is not possible to realization because of construction limitations. Therefore, four displacement sensors are set in the one direction (vertically).

This concept allows estimating the value of stiffness that result from experimental data, such as load signal and displacement signal. In Fig. 4b, the idea of processing of obtained signals is presented.

\subsection{SWS prototype}

Taking into consideration all requirements described above, the realization of the project is shown in Fig. 5 . The simulated loading is generated by the compact hydraulic system, that hydraulic diagram is presented in Fig. 6 . The hydraulic system is supplied by a compact hydraulic power pack (using mini HPU), which can produce pressure $\Delta p=220$ bar at flow $Q=1.5 \mathrm{l} / \mathrm{min}$. For controlling the pressure at outlets A and B (see Fig. 6) of proportional valve (produced by Parker, D1FVE02CC0NW53 [20]), the pressure converters Wika S20 [21] are applied. The hydraulic system allows for flow Q as high as $10 \mathrm{l} / \mathrm{min}$ and $\max \Delta p=350$ bar. The hydraulic system includes also the pressure measuring system which contains two redundantindependent pressure converters Wika S20. These converters enable to control actual values of pressure; the control in needed in the proportional valve control system. The system was previously tested in the frequency range up to $15 \mathrm{~Hz}$, the results have not shown any significant differences between the set and the measured pressure. For expected displacement values below $0.5 \mathrm{~mm}$ at $1 \mathrm{~Hz}$ and at pressure lower than $30 \mathrm{bar}$, the system should generate 
(a)

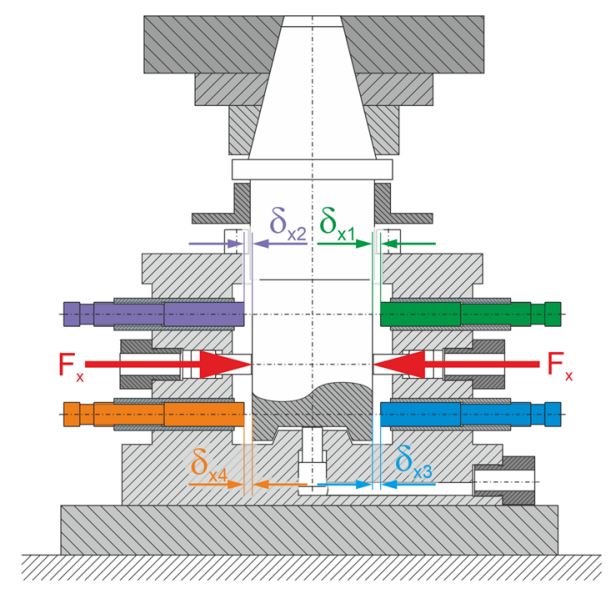

(b)
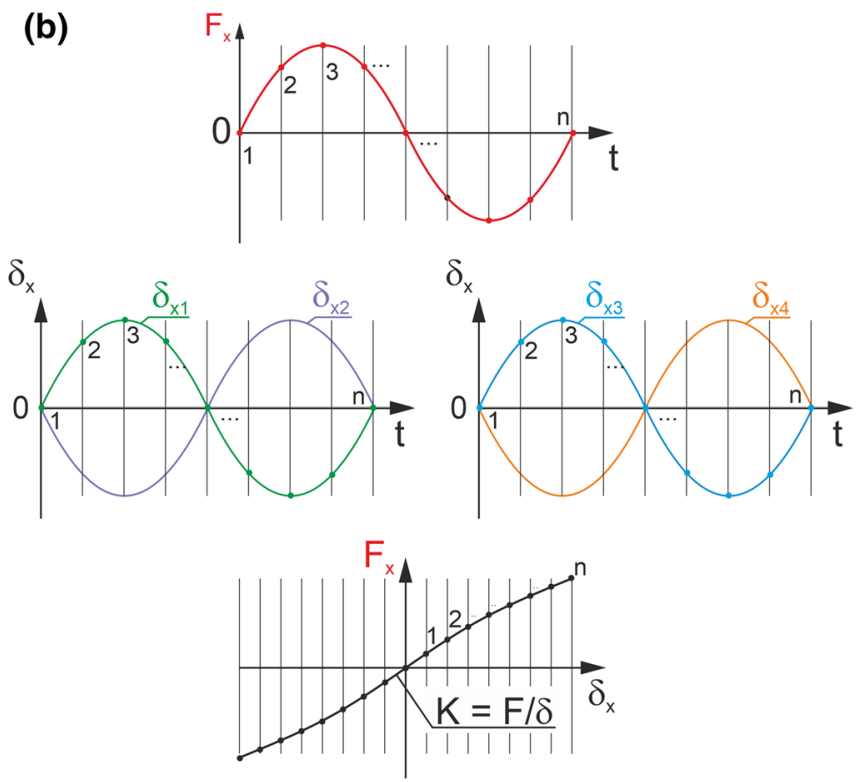

Fig. 4 Simplified scheme of SWS conception; a sensors and actuators setup for one direction, $\mathbf{b}$ signals processing

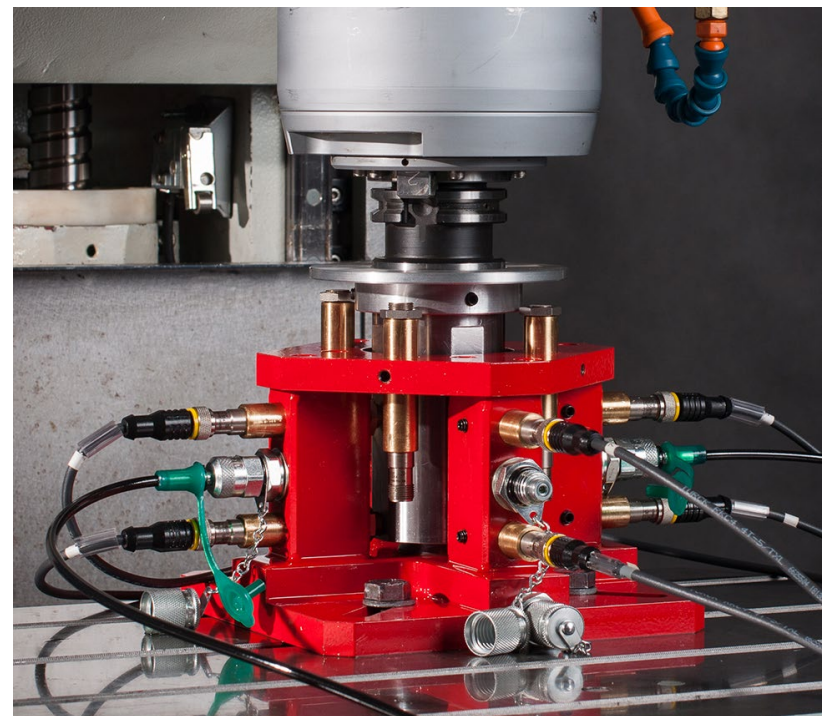

Fig. 5 Mechanical part of SWS-the prototype of the system

the instantaneous flow $0,0023 \mathrm{~cm}^{3} / \min$ (for $15 \mathrm{~Hz}-0.035$ $\mathrm{cm}^{3} / \mathrm{min}$ ). Using Mini HPU guaranties maximum flow $1100 \mathrm{~cm}^{3} / \mathrm{min}$ at $200 \mathrm{bar}$, thus, the required parameters are fulfilled. The control signal is generated by function generator UEISIM 600-1G [22] which is needed to control the Parker's proportional hydraulic valve. Also, the UEISIM $600-1 \mathrm{G}$ is used as a data acquisition device. It registers simultaneously signals from six pairs of displacement sensors (Baumer IPRM 12I9505/S14 [23]) and from two pressure sensors.
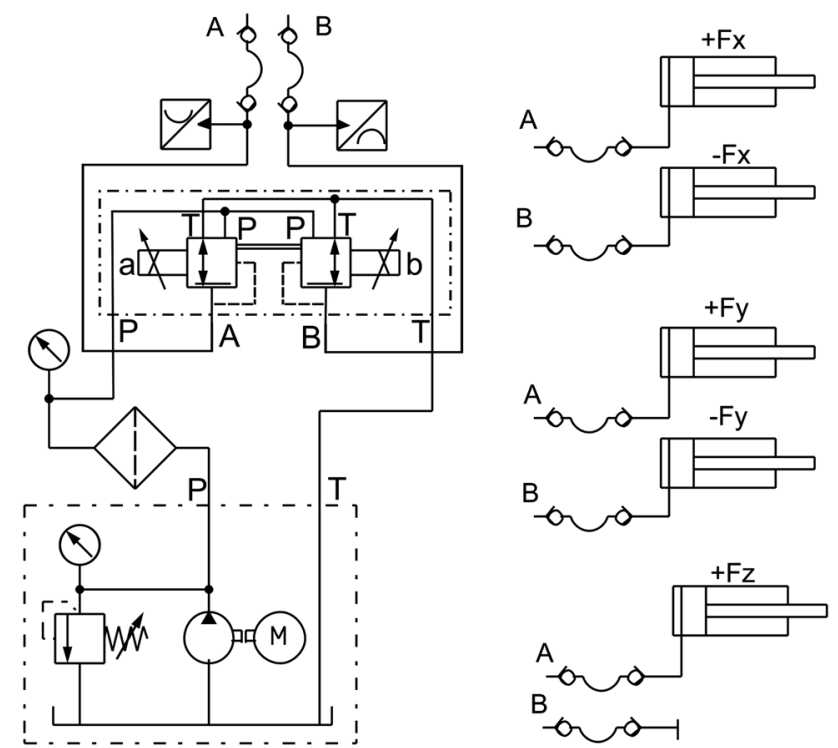

Fig. 6 Hydraulic diagram of the load generator for SWS

\subsection{Numerical analysis of stiffness of SWS}

The mechanical part of SWS mounted on the machine tool is integrated with the structural loop of machine tool-it creates closed loop of loads. The proposed approach requires high stiffness of SWS in comparison to MTHW system. Hence, the static analysis of SWS model was performed using FEM method. The aim of the analysis was to determine the values of relative displacements between the contact surfaces of the arbour and actuators (see Fig. 7). 
Fig. 7 FEM analysis of the SWS

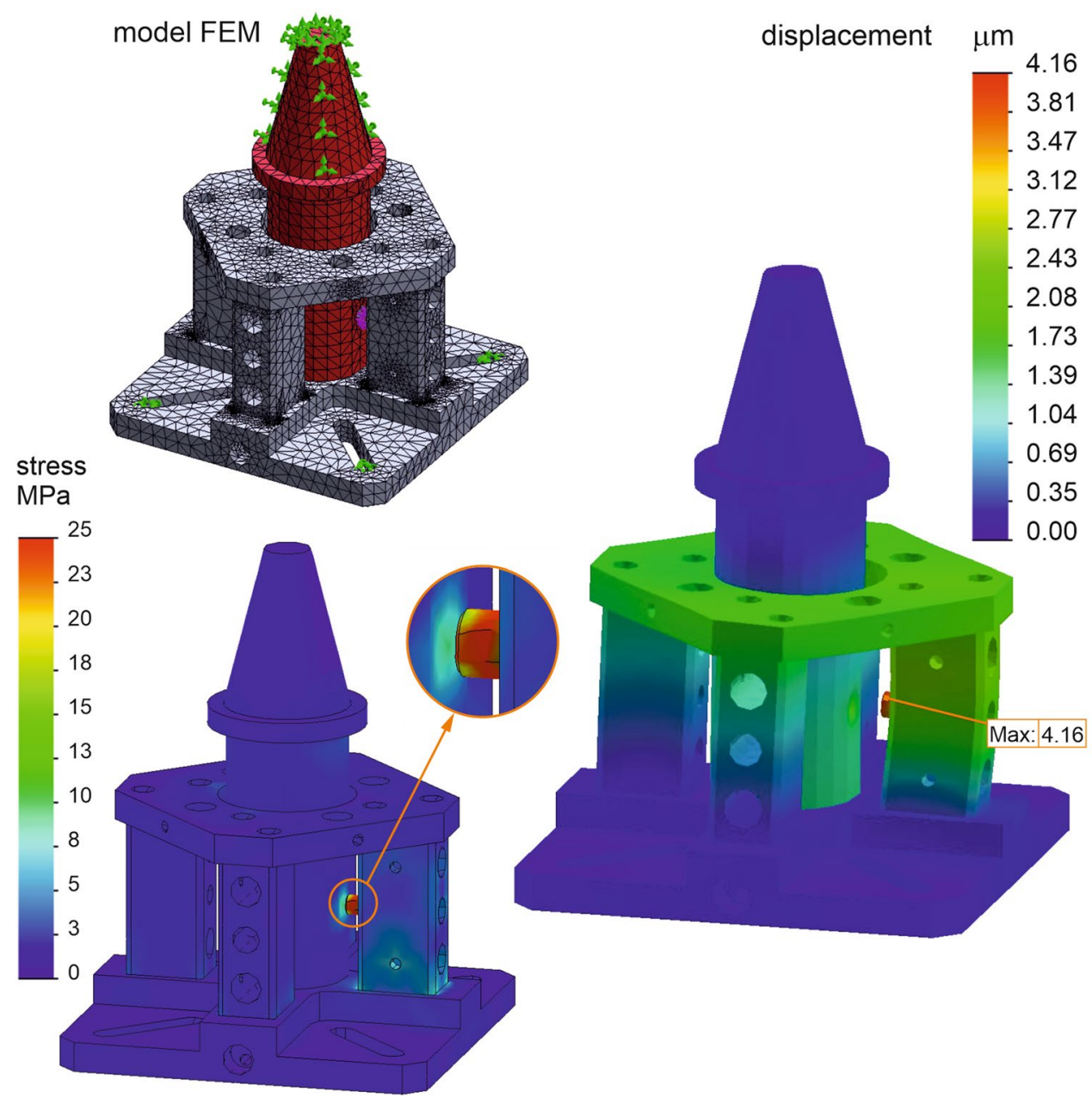

The analysis was carried out for loading force $F=2 \mathrm{kN}$ and the greatest value of the displacement was $7 \mu \mathrm{m}$. The obtained value is within acceptable limits comparing with expected displacements caused by loads of machining process. Calculated stiffness coefficient of the mechanical part of SWS equals to $286 \mathrm{~N} / \mu \mathrm{m}$. This means, it is more than 20 times greater than typical expected stiffness value of machine tools (the stiffness value of medium-sized machine tools usually is below $10 \mathrm{~N} / \mu \mathrm{m}[1]$.

\section{Experimental investigation of SWS}

\subsection{Experimental procedure}

The aim of the experimental investigation was to verify of the prototype of SWS. The mechanical part of the SWS was installed on the machine tool table. The hydraulic power unit, load control system and the data acquisition system were placed in a framework situated next to the machine (shown in Fig. 8). The measurement tests for nine positions of the SWS in the machine workspace were carried out. The

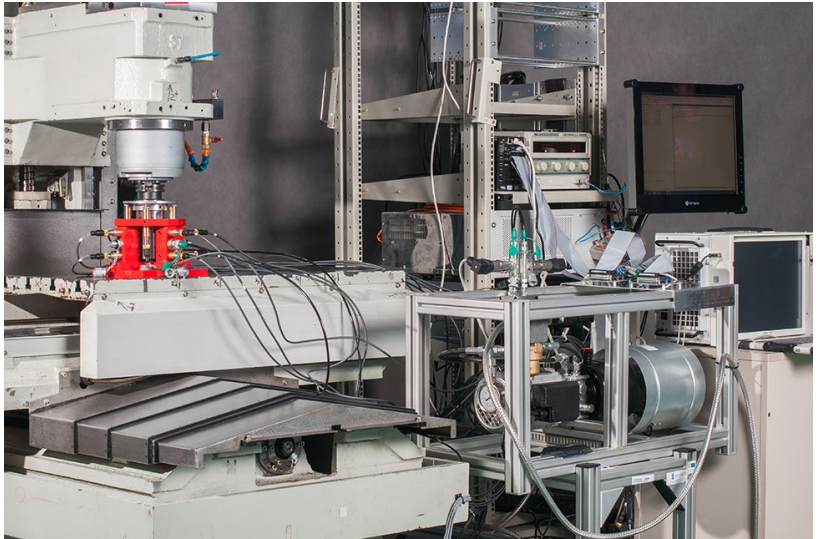

Fig. 8 View of the SWS installed on the table of milling centre

position of the mechanical part of SWS was changed in the $X Y$ plane. However, the position respect to the $Z$-axis did not change. The arrangement of measuring positions (marked with numbers 1-9) is presented in Fig. 8.

The working space of the machine tool used in this test is $600 \mathrm{~mm}$ long in the $X$-direction, $350 \mathrm{~mm}$ long in 
the $Y$-direction, and $450 \mathrm{~mm}$ in the $Z$-direction. Measuring points were placed equally on the plane of the machine table. The point number 5 was in the middle (see Fig. 9). The coordinates of the points are presented in Table 1.

The body of the mechanical part of SWS was fastened directly to the machine tool table using T-bolts and nuts. In the proposed method, to transmit the load to the spindle, the solid arbour is used. The arbour is fastened in the spindle as a typical tool with ISO 40 conical-tipped shank. This means that the SWS can be mounted without interfering with the machine's structure. What is more, for the mounting process only standard equipment needs to be used. The tool overhang that results from the arbour length was $102 \mathrm{~mm}$ (see Fig. 10).

Machine tool stiffness was determined in each of nine points of the adopted plan (as shown in Fig. 9). At each position the force was generated in sequence: along $X$-axis, $Y$-axis, and then along $Z$-axis. The loading process in the $X$-axis and $Y$-axis was realized as a symmetrical alternating signal with respect to zero. This means that in each cycle the control signal caused the change in the direction (plus or minus) of the applied load to the opposite. In the $Z$-axis only a positive pulse signal was used. This means the load was directed upwards.

\subsection{Measured signal processing}

During the measurement test, 14 signals were processing altogether. Channels numbered from 1 to 12 were registering all changes of relative displacements between the active and passive part of the loading device (see in Fig. 11). In this approach, the displacement sensors work in differential mode which means that channels of each sensor pair (e.g., sensor no 1 and no 2) are combine. This setting is used to average the signals and linearize the sensors characteristics.

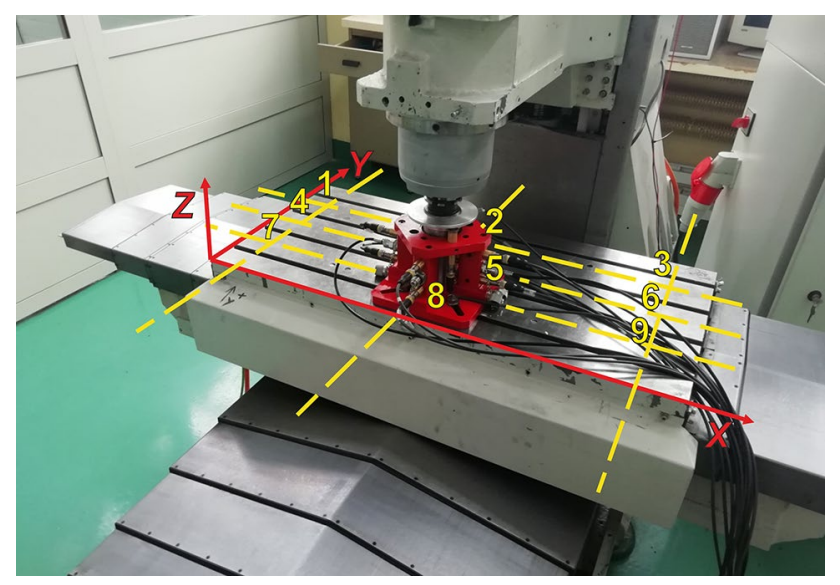

Fig. 9 Arrangement of measuring points on the machine tool $X Y$ plane (an actual measurement at point number 8)
Table 1 Coordinates of measurements positions in machining space

\begin{tabular}{lrll}
\hline Number of position & $X, \mathrm{~mm}$ & $Y, \mathrm{~mm}$ & $Z, \mathrm{~mm}$ \\
\hline 1 & 20 & 229 & 37 \\
2 & 295 & 229 & 37 \\
3 & 570 & 229 & 37 \\
4 & 20 & 127 & 37 \\
5 & 295 & 127 & 37 \\
6 & 570 & 127 & 37 \\
7 & 20 & 25 & 37 \\
8 & 295 & 25 & 37 \\
9 & 570 & 25 & 37 \\
\hline
\end{tabular}

The way the SWS is constructed enables obtaining displacement signals in $X$ and $Y$ directions from two pairs of displacement sensors. Due to the symmetrical arrangement of sensors pairs relative to the points of action of actuators, the indications of the relevant sensors can be averaged. Then, the displacement at the point of force application can be determined. In the vertical direction, there are four sensors symmetrically arrange around the actuator's axis along $Z$-axis. Hence, the signals of these sensors may also be averaged to determine the displacement in the $Z$ axis.

Pressure signals were registered by channels number 13 and 14 (Fig. 11) at outlets of the proportional hydraulic valve. Based on these signals and cylinder parameters the load values were calculated.

All signals are recorded by a real-time control system. The registered signals are sent to the computer via Ethernet (ETH). Then, by using DSP software the following actions take place: wavelet denoising, period averaging, stiffness calculation, data analysis and results presentation.

Signal processing is presented on the example of measurements in position no. 5 (see Fig. 9), in the $X$-axis direction $(5 \times)$. Based on Fejer-Korovkin level 10 wavelet filter

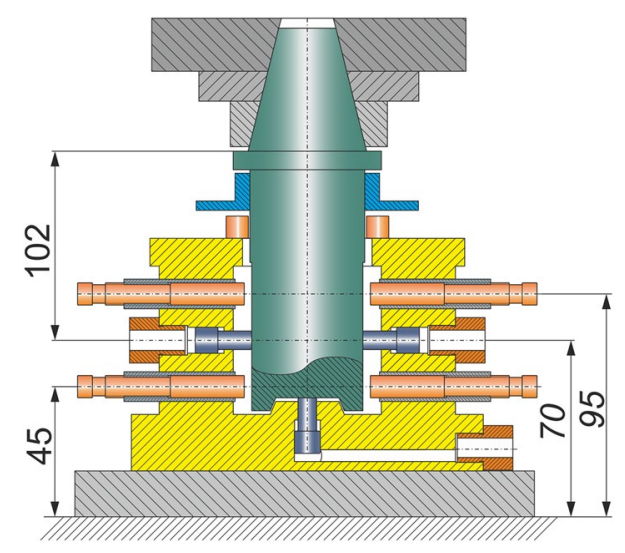

Fig. 10 Scheme of the SWS with marked distances between measuring points and the elements of the machine tool 


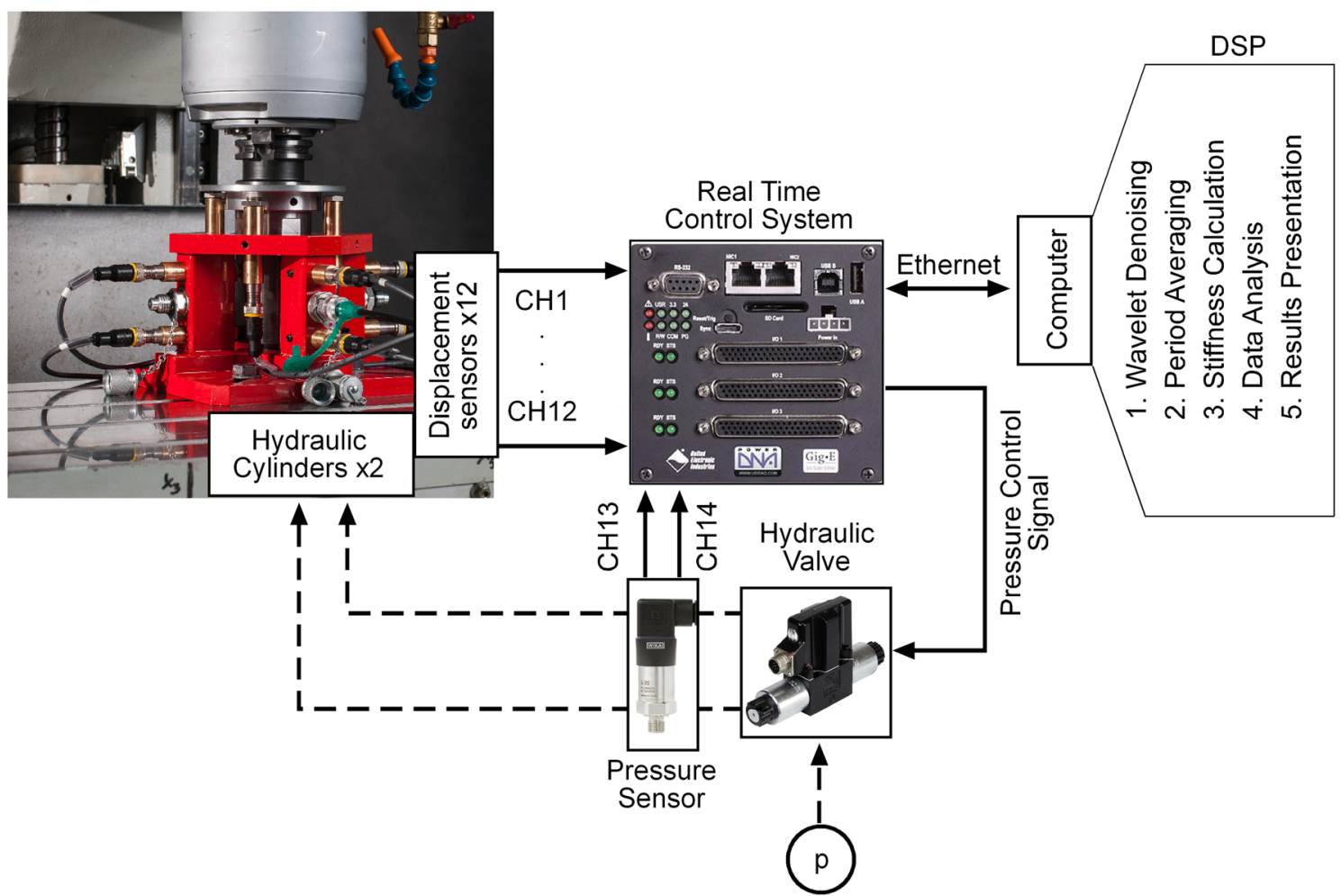

Fig. 11 Block diagram of signal processing in the signal acquisition and control system

the signal is filtered to reject measuring noise. The filtration process is shown in Fig. 12.

Then, the signal was divided into individual periods. Every registered measurement contained 20 periods of a generated harmonic wave of frequency $0.25 \mathrm{~Hz}$. Figure 13 shows five selected periods (each marked with different colour).

In Fig. 14 one period of each analysed signals is shown, respectively (a) displacement and (b) force (load). It can be noticed that in Fig. 14b there are some disturbance of (a)
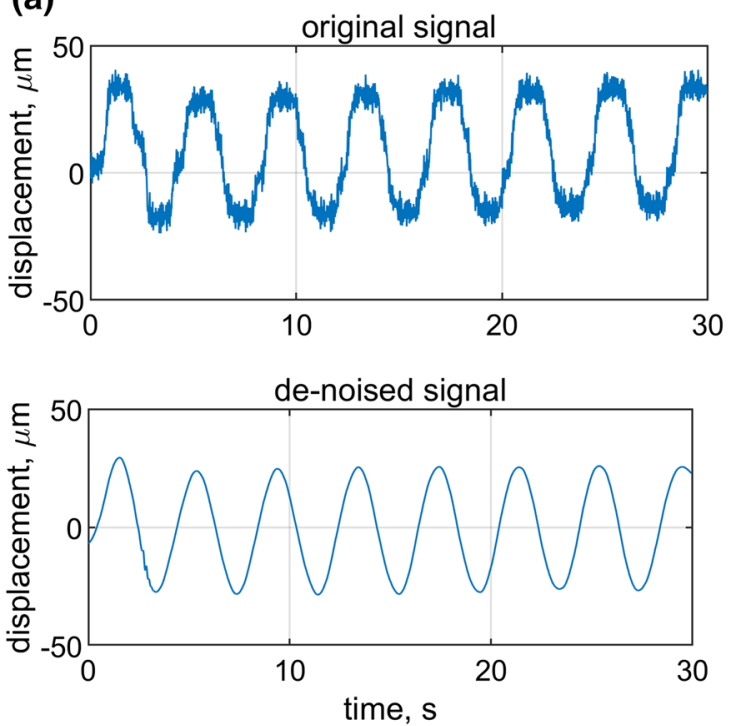

(b)
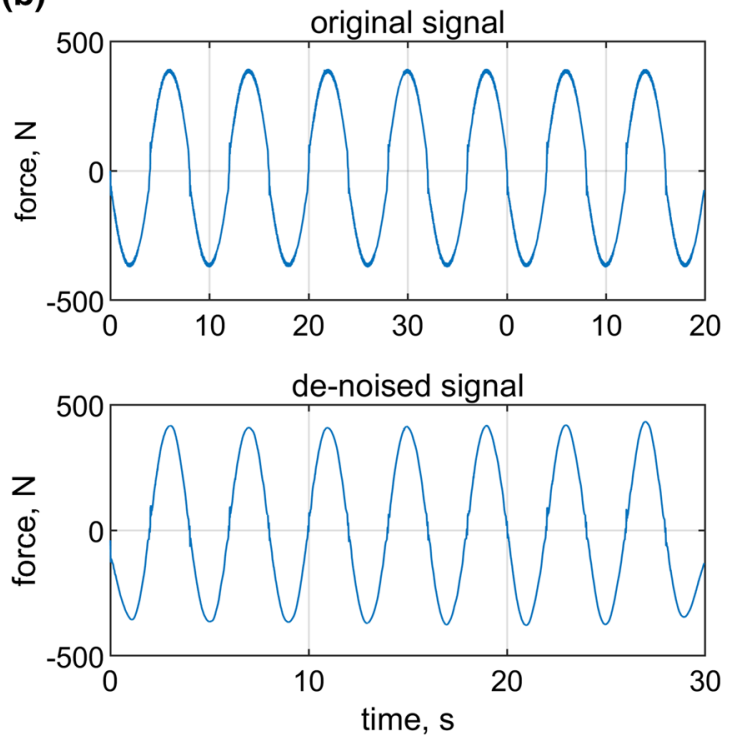

Fig. 12 Measured signals before and after filtration process $\mathbf{a}$ displacement signal, $\mathbf{b}$ force (load) signal 

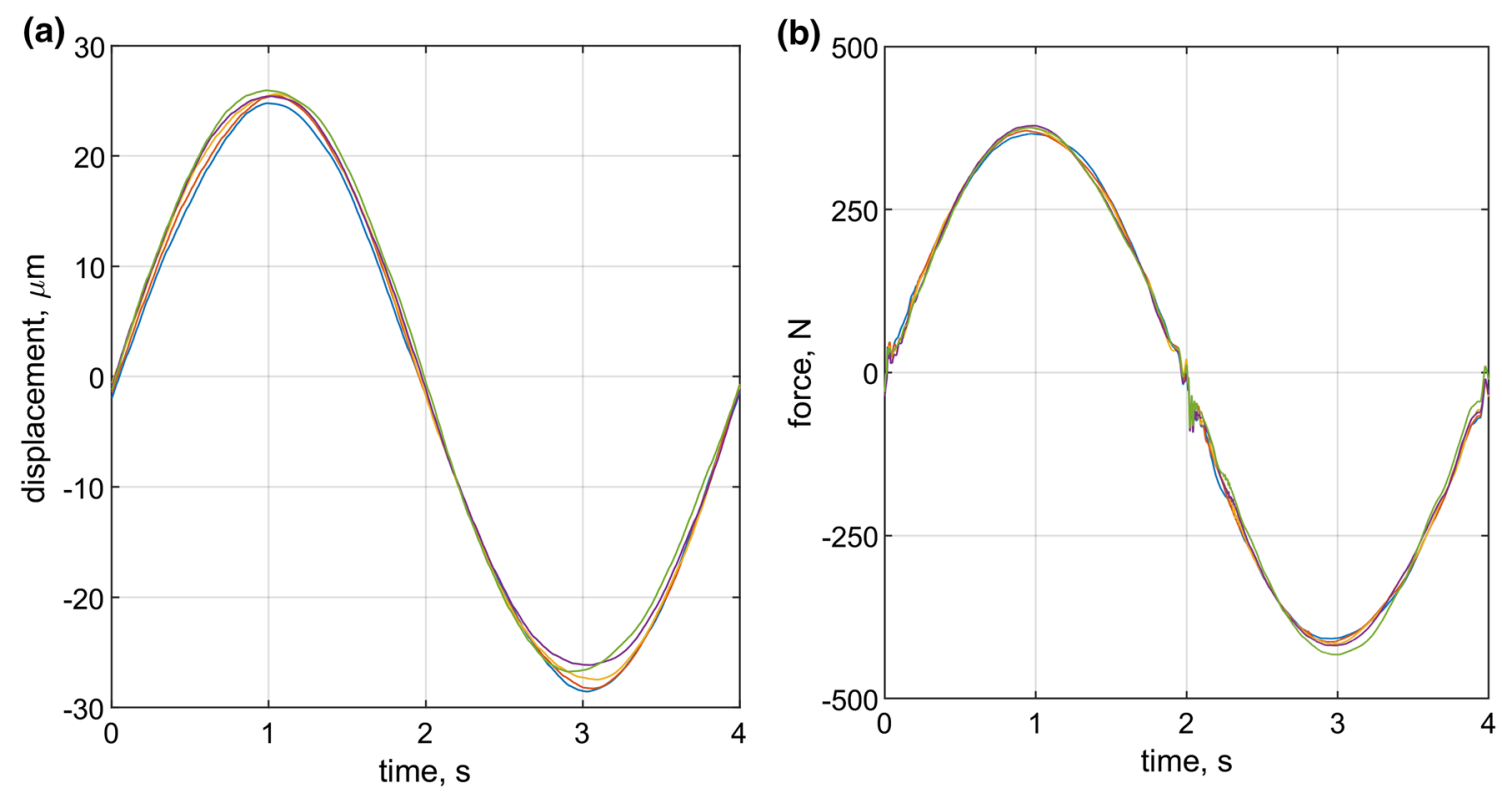

Fig. 13 Exemplary periods of signals: a displacement signal, $\mathbf{b}$ force (load) signal
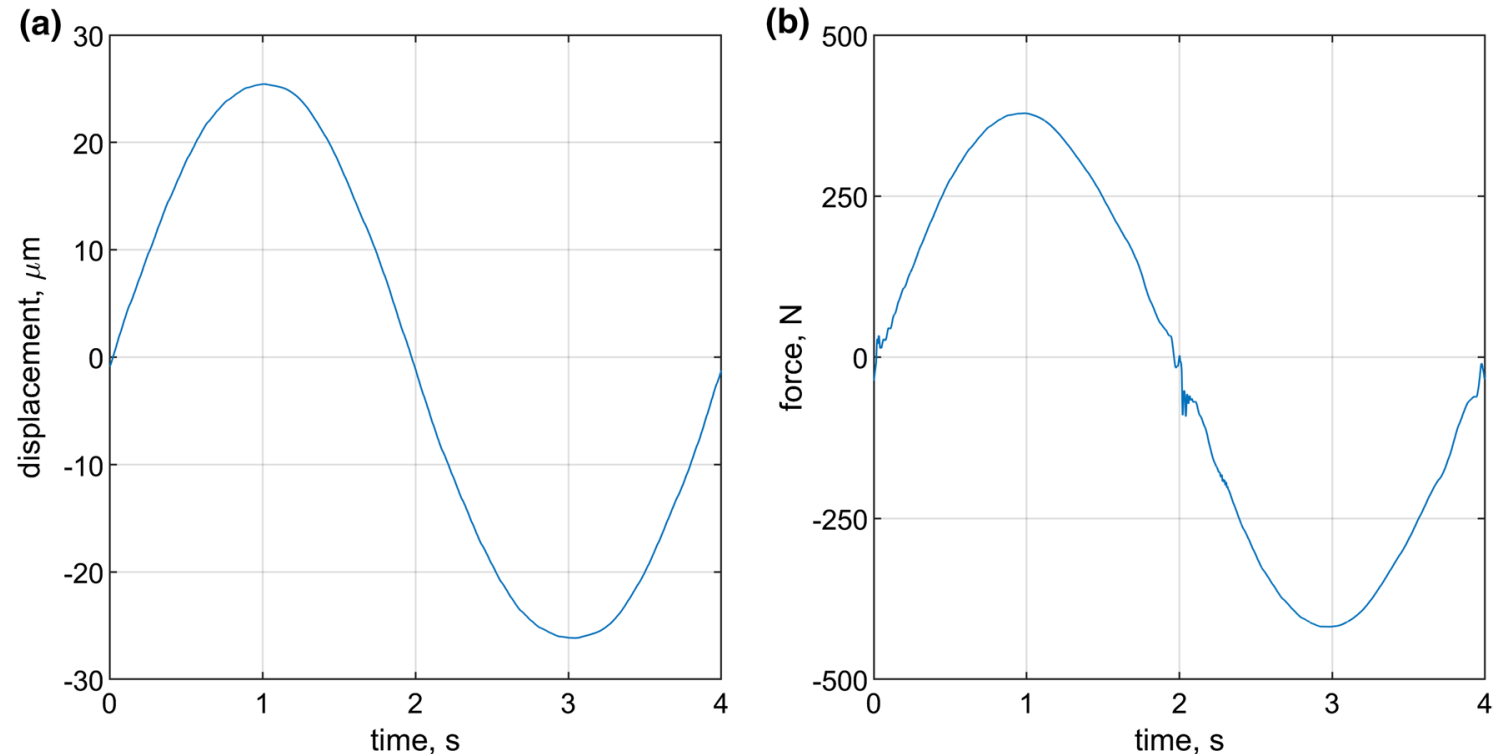

Fig. 14 One period of analysed signals: a displacement signal, $\mathbf{b}$ force (load) signal

harmonic signal. These errors can be caused by the inertia of the proportional hydraulic valve and may occur if the valve's direction of the operation changes. However, the occurrence of the slight effect around values close to zero should not affect the accuracy of calculations.

\section{Experimental results and discussion}

Stiffness coefficients were determined for a single period and this process was repeated 20 times (in line with the 


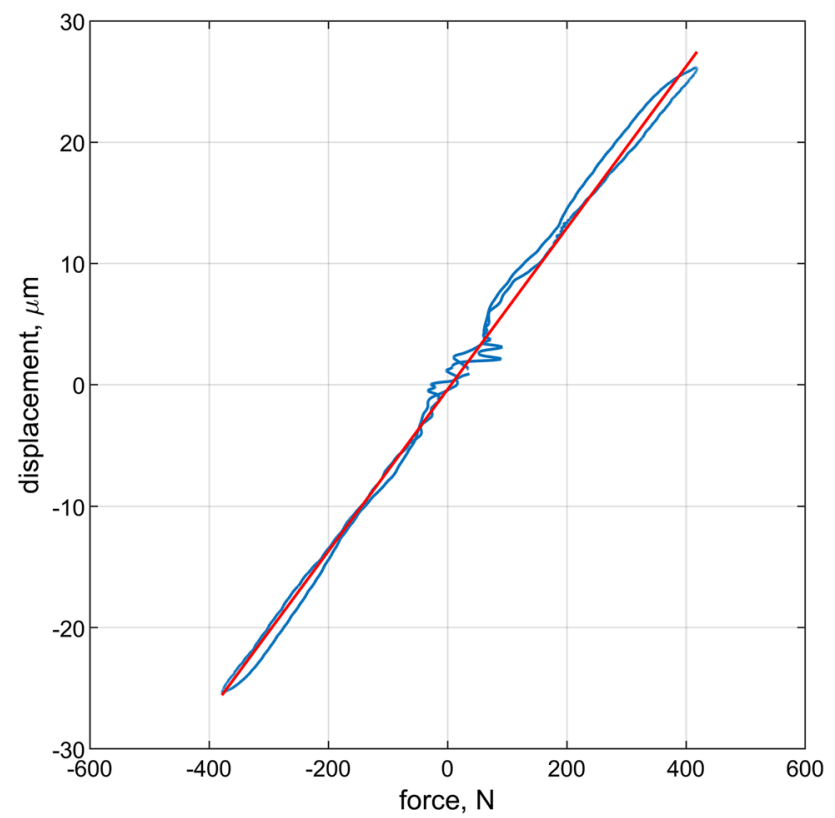

Fig. 15 Stiffness characteristics for measurements at point $1 Y$

number of cycles) then obtained values were averaged. For these results, the standard deviations and linear correlation coefficients were determined. Figure 15 shows an exemplary characteristic of stiffness for one of the measuring points. The values of stiffness in $X, Y$ and $Z$ directions at nine measuring positions are shown in Table 2 .

Figure 16 shows the calculated stiffness results for $X Y$ plane. Each presented surface represents the stiffness in different direction of the applied force: (1) in $X$ direction, (2) in $Y$ direction and (3) in $Z$ direction. The most noticeable differences are between the range of stiffness values in the directions $X$ and $Z$. The results deviate between $8.0 \mathrm{~N} /$ $\mu \mathrm{m}$ and $18.5 \mathrm{~N} / \mu \mathrm{m}$. It can be assumed that these variations are caused by the configuration of the carrying system

Table 2 Force to displacement ratio N/um at nine positions in the machine workspace. The \pm values are range of repeated measurements

\begin{tabular}{lrrr}
\hline $\begin{array}{l}\text { Number of posi- } \\
\text { tions }\end{array}$ & $F / d \mathrm{x}, N / \mu \mathrm{m}$ & $F / d \mathrm{y}, N / \mu \mathrm{m}$ & $F / d \mathrm{z}, N / \mu \mathrm{m}$ \\
\hline 1 & $10.9 \pm 0.1$ & $15.0 \pm 0.1$ & $17.8 \pm 0.5$ \\
2 & $9.0 \pm 0.1$ & $13.8 \pm 0.1$ & $18.5 \pm 0.5$ \\
3 & $8.8 \pm 0.2$ & $12.2 \pm 0.2$ & $17.5 \pm 0.6$ \\
4 & $8.9 \pm 0.1$ & $11.4 \pm 0.3$ & $17.5 \pm 0.6$ \\
5 & $8.0 \pm 0.1$ & $11.3 \pm 0.3$ & $17.9 \pm 0.4$ \\
6 & $9.0 \pm 0.1$ & $12.6 \pm 0.1$ & $17.0 \pm 0.5$ \\
7 & $12.8 \pm 0.1$ & $13.1 \pm 0.1$ & $16.4 \pm 0.4$ \\
8 & $9.2 \pm 0.1$ & $13.0 \pm 0.5$ & $17.8 \pm 0.5$ \\
9 & $10.2 \pm 0.6$ & $10.7 \pm 0.3$ & $16.0 \pm 0.5$ \\
\hline
\end{tabular}

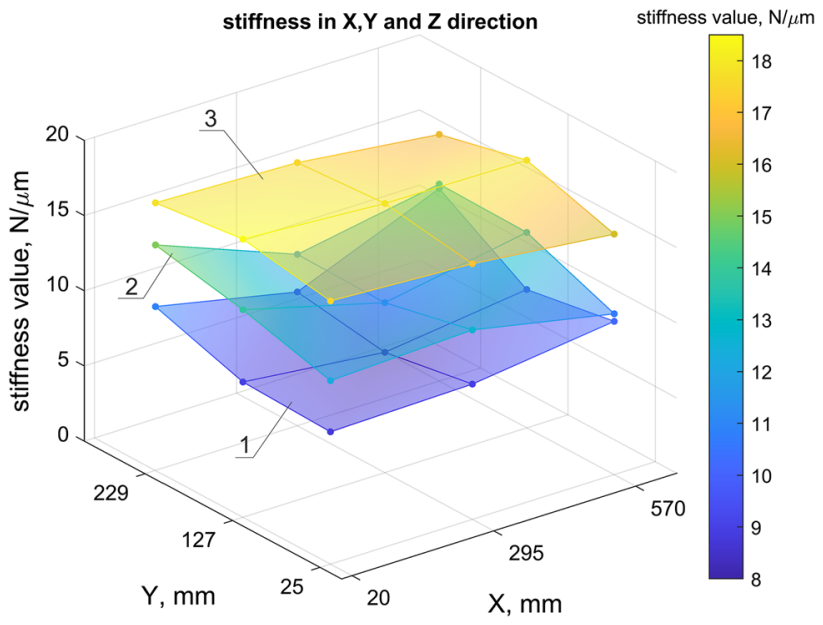

Fig. 16 Results of quasi-static stiffness for $X Y$ plane measured at nine positions in the machine workspace. The $Z$-axis represents the values of stiffness Three surfaces represent stiffness values in $X$ (1), $Y$ (2) and $Z$ (3) directions, respectively

(complexity of geometric and structural elements) of tested machine tool. Some major uncertainty sources were considered, such as the measurement instrumentation uncertainty of displacement sensors and pressure sensors (in according to the instrument supplier). The most significant uncertainty value was for position number 7 and it was: in $X$ direction $1.41 \mathrm{~N} / \mu \mathrm{m}$, in $Y$ direction $1.70 \mathrm{~N} / \mu \mathrm{m}$ and in $Z$ directions $1.84 \mathrm{~N} / \mu \mathrm{m}$. The environmental conditions were within normal range for used equipment.

Obtained results confirm that the estimating of stiffness coefficients in machine workspace plays a significant role in the accuracy evaluation process. As the results vary considerably according to different positions in the investigated space that means that position and orientation in workspace can influence machining process and its accuracy.

Experimental tests were performed to verify the prototype of the novel system (SWS) and assess its usability. The full test plan included measurements in only one plane of the machining space. The obtained results (presented in Table 2) show significant differences with respect to each measuring positions. The values of stiffness coefficients change along individual machine axis and strongly vary depending on the direction. Satisfactory results of force measurements (pressure measurements in hydraulic working lines) were obtained. Thus, the possibilities of controlling the valve responsible for controlling pressure in the hydraulic circuit were confirmed. What is more, the SWS allows synchronous recording of many signals in real time, too. The time of change in positions of the SWS in the machine workspace is on an acceptable level, in terms of industrial research. Given the above, a conclusion can be drawn that these conducted tests confirmed the functionality of the prototype measuring system. 


\section{Conclusions}

The paper presents a novel method and an innovative device (called Stiffness Workspace System) to estimate the machine tool stiffness. The method is based on measurements of displacements and force values at the functional point (the interface between the toolholder and the workpiece). The system enables to carry out the displacement measurements simultaneously using 12 sensors. The SWS design provides the possibility of applying the loads simultaneously in three directions, in line with machine axes. This gives information needed to determine the stiffness values at a certain location and direction of machine workspace. The uncomplicated and fast process of the device assembling on the machine table allows measuring quasi-static stiffness at each possible point in machining space.

The above discussion and analysis of obtained results indicate that stiffness measurements conducted in various points of machine workspace are crucial. According to this research, it can be stated that the variability of stiffness coefficients depends on both the position in workspace and the direction of the applied force. It can be drawn that the main reason for this variability may be the machine tool construction and the actual configuration of its moving components. This proposed method improves determining the spatial stiffness distribution in the machining space which can be valuable for both machine tool manufacturers and users.

Acknowledgements His work was supported by the Polish National Science Centre (NCN) within the project entitled: Methodology of calculations and experimental tests of the properties of machine tool carrying systems at many points in the machining space, under the grant N N502 665240.

Author contributions Piotr Pawełko: conceptualization, formal analysis, investigation, methodology, resources, validation, visualization, writing —original draft. Daniel Jastrzębski: conceptualization, funding acquisition, methodology, project administration, resources, supervision, validation, visualization, writing — original draft, writing - review $\&$ editing. Arkadiusz Parus: data curation, formal analysis, investigation, resources, software, validation, visualization. Joanna Jastrzębska: software, validation, visualization, writing — original draft, writingreview \& editing.

Funding This work was supported by the Polish National Science Centre $(\mathrm{NCN})$ within the project entitled: Methodology of calculations and experimental tests of the properties of machine tool carrying systems at many points in the machining space, under the agreement N N502 665240 .

\section{Declarations}

Conflict of interest The authors declare that they have no conflict of interest.

Ethical approval This article does not contain any studies with human participants or animals performed by any of the authors.
Open Access This article is licensed under a Creative Commons Attribution 4.0 International License, which permits use, sharing, adaptation, distribution and reproduction in any medium or format, as long as you give appropriate credit to the original author(s) and the source, provide a link to the Creative Commons licence, and indicate if changes were made. The images or other third party material in this article are included in the article's Creative Commons licence, unless indicated otherwise in a credit line to the material. If material is not included in the article's Creative Commons licence and your intended use is not permitted by statutory regulation or exceeds the permitted use, you will need to obtain permission directly from the copyright holder. To view a copy of this licence, visit http://creativecommons.org/licenses/by/4.0/.

\section{References}

1. Archenti A, Nicolescu M, Casterman G, Hjelm S. A new method for circular testing of machine tools Under loaded condition. Proc CIRP. 2012;1:575-80. https://doi.org/10.1016/j. procir.2012.05.002.

2. ISO 230-1:2012, Test code for machine tools. Part 1: geometric accuracy of machines operations under no-load or finishing conditions, ISO, Geneva (2017).

3. ISO 10791-7:2020 Test conditions for machining centres - Part 7: Accuracy of finished test pieces, ISO, Geneva (2020).

4. Te-Yen HD, Lee J-J. On obtaining machine tool stiffness by CAE techniques. Int J Mach Tools Manuf. 2001;41:1149-63. https://doi.org/10.1016/S0890-6955(01)00012-8.

5. Jastrzębski D. Modelling of static properties of load-carrying system of machines tools using hybrid finite element method. Adv Manuf Sci Technol. 2008;32(1):9-28.

6. Jastrzębski D. Application of the hybrid finite element method in modeling of static properties of machine tools load-carrying subsystems. Adv Manuf Sci Technol. 2008;32(2):5-20.

7. Salgado MA, López de Lacalle LN, et al. Evaluation of the stiffness chain on the deflection of end-mills under cutting forces. Int J Mach Tools Manuf. 2005;45(6):727-39. https:// doi.org/10.1016/j.ijmachtools.2004.08.023.

8. Dunaj P, Berczyński S, Pawełko $\mathrm{P}$, et al. Static condensation in modeling roller guides with preload. Arch Civ Mech Eng. 2019;19(4):1072-82. https://doi.org/10.1016/j. acme.2019.06.005.

9. Wu J, Wang J, et al. Study on the stiffness of the 5-DOF hybrid machine tool with actuation redundancy. Mech Mach Theory. 2009;44(2):289-305. https://doi.org/10.1016/j.mechmachth eory.2008.10.00.

10. Albrecht A, Park S, Altintas Y, Pritshow G. High frequency bandwidth cutting force measurement in milling using capacitance displacement sensors. Int J Mach Tools Manuf. 2005;45(9):9931008. https://doi.org/10.1016/j.ijmachtools.2004.11.028.

11. Sarhan A, Matsubara A. Investigation about the characterization of machine tool spindle stiffness for intelligent CNC end milling. Rob Comp Integr Manuf. 2015;34:133-9. https://doi. org/10.1016/j.rcim.2014.12.001.

12. Wang X, Guo Y, Chen T. Measurement research of motorized spindle dynamic stiffness under high speed rotating. Shock Vib. 2015;1:1-11. https://doi.org/10.1155/2015/284126.

13. Matsubara A, Sawamura R, Asano K, Muraki T. Non-contact measurement of dynamic stiffness of rotating spindle. Proc CIRP. 2014;14:84-487. https://doi.org/10.1016/j.procir.2014.03.012.

14. Rantatalo M, Aidanpaa J, et al. Milling machine spindle analysis using FEM and non-contact spindle excitation and response measurement. Int J Mach Tools Manuf. 2007;47(7-8):1034-45. https://doi.org/10.1016/j.ijmachtools.2006.10.004. 
15. Gao X, Li B, Hong J, Guo J. Stiffness modeling of machine tools based on machining space analysis. Int J Adv Manuf Technol. 2016;86:2093-106. https://doi.org/10.1007/s00170-015-8336-z.

16. Archenti A, Nicolescu M. A top-down equivalent stiffness approach for prediction of deviation sources in machine tool joints. CIRP Ann Manuf Technol. 2017;66:487-90. https://doi. org/10.1016/j.cirp.2017.04.066.

17. Szipka K, Laspas T, Archenti A. Measurement and analysis of machine tool errors under quasi-static and loaded conditions. Preci Eng. 2018;51:59-67. https://doi.org/10.1016/j.precisione ng.2017.07.011.

18. Tönshoff HK, Wulfsberg JP, et al. Developments and trends in monitoring and control of machining processes. ANNALS CIRP. 1988;37(2):611-22. https://doi.org/10.1016/S0007 -8506(07)60758-6.

19. Byrne G, Dornfeld D, et al. Tool Condition Monitoring (TCM) - the status of research and industrial application. ANNALS
CIRP. 1995;44(2):541-67. https://doi.org/10.1016/S0007 -8506(07)60503-4.

20. Parker: Proportional Pressure Reducing Valve Catalog - D1FV. https://ph.parker.com/gb/en/proportional-pressure-reducing-valve -series-d1fv-d1fv-ee.

21. High performance pressure transmitter. WIKA Datasheet S-20, 4, 2013.

22. UEISIM 600, United Electronic Industries, www.ueidaq.com.

23. High precision analogue sensors IPRM 12I9505/S14. www.baume r.com.

Publisher's Note Springer Nature remains neutral with regard to jurisdictional claims in published maps and institutional affiliations. 